\title{
Weld Repair and the Importance of Analyzing Failure Mode
}

\author{
Daniel J. Thomas
}

Submitted: 8 February 2016/Published online: 22 February 2016

(C) ASM International 2016

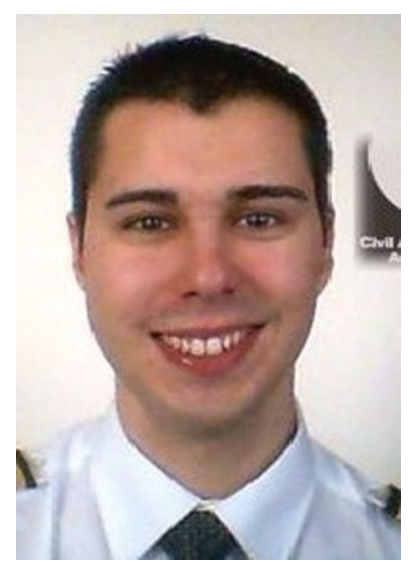

At any time in industry, when a weld fails in any critical component, this usually results in loss of production or in extreme cases a shut down altogether of the production process. When this happens, typically we look for the fastest way to repair the system in order to put it back into service. The pressure is on to fix the weld, quickly and efficiently. However, when we consider that weld failure happens because of numerous reasons, is it not more important to find out why it has failed in the first place? And subsequently using this knowledge will prevent that weld from failing again.

On-site welding processes are very important across heavy industry. The most commonly used processes used on site are shielded metal arc welding (SMAW) and manual metal arc welding (MMA). Welding in industry is

D. J. Thomas $(\bowtie)$

College of Engineering, Swansea University, Swansea, UK

e-mail: d.j.thomas@swansea.ac.uk

often carried out in exposed cold conditions, in winds and sometimes even in the rain. These environmental factors can make welding very challenging. I have an appreciation of this, having previously worked in the steel manufacturing and power generation industries as an on-site engineer. We often carried out SMAW welding up to $100 \mathrm{~m}$ off the ground, welding dreaded high-silicon content steel plates together in atrocious conditions. Trying to control the arc and weld pool becomes almost impossible when the wind is howling, as it often is here in Wales.

In conditions like this, the types of welding electrodes, current, and weld position become critical. Departure from these standards can result in the wrong degree of heat being introduced into the workpiece, which can subsequently cause fracture some years down the line. When welding, it is easy to lose concentration of the weld pool and to produce an undercuts or incomplete penetration. Wind can affect the gas flow (SMAW) with air contaminating the weld, which can cause porosity. There are so many other factors that can significantly weaken the weld, which will result in premature failure. There are numerous other reasons why weld failure happens. The key reasons why welds fail prematurely in services are

1. The material and its chemistry properties.

2. Inappropriate weld specification during the design process.

3. Defects resulting from the welding processes.

4. Excessive unanticipated service conditions.

The investigation process following weld failure is critical. Often, the personnel first on the scene will not necessarily be trained in the science of failure analysis. However, some investigative steps should always be taken. It is important to ensure that nothing is moved, reassembled, or repaired prior to the failure investigation. Document the condition 
of the weld and surrounding parent material when the failure was identified. Write down all the external factors that may have had an effect on the weld, and which were present during its failure. It is good to take photographs of the surrounding location and detailed observations of the fracture and the area around the damaged regions.

The most important factor during the early phase of inspection is not to supply an initial opinion. These are often based on as yet unfounded speculation for the cause of the weld fracture. It is important only to present a reason only once all of the information collected has been put together. Inappropriate welding technique, hydrogen embrittlement, weld creep, corrosion, and weld fatigue are often the first factors that are blamed for the failure. There is also the combination of factors, in the case of off shore oil drilling industry, in which harsh marine environmental corrosion fatigue is often present. But at this stage, there are so many things which could have caused failure.

An inspection of the weld failure profile under low magnification, including the details of the direction of failure and size, can be measured accurately. The condition of the weld toe and details as to whether the failure emanated from this region is very important. The profile of the fracture can act to provide us with a history of the failure. A fracture is initially characterized by its size and the orientation; longitudinal, transverse, or along the weld bead. Further, we need to know its position relative to the weld bead itself and which side of the weld bead; if it is near the heat-affected zone (if still visible) or near the parent material.

If the fracture is open then inspect the surfaces to determine internal defects, including: worm holes, nonmetallic inclusions, or for any indications of fatigue failure in the form of striation marks. The presence of macroscopic deformations in the fracture surface can be assessed to determine if the failure was ductile, in which the fracture will appear deformed. Or brittle, in which there will be no deformation. Has a fatigue crack grown deep into the parent material? Internal microcracks can in some rare cases remain in the parent material and subsequently will grow through the material following a repair.

Specific colors noticed on the surfaces should be studied. This offers indications about temperature of the application as does any signs of oxidation. Any blue marks indicate if the weld was overheated or rapidly quenched. The presence of arc strikes on the surface may indicate improper starting conditions. These contacts can cause the origin of fatigue failure. The parent material should finally be determined in order to check its specification. Before these essential phases, a repair to the weld should not be attempted. Having a range of information allows for the appropriate selection of the correct repair procedures and subsequent repair electrode type or filler wire. Failure analysis becomes critical in the repair process.

I was once told that if a fracture formed from a weld it can only be repaired if the parent material and the conditions are exactly as they were during the original fabrication. As a result, there should be no heat treatment or surface properties introduced in the region around the weld. However, if a weld is restored exactly to its original condition, then another breakage can occur. Before attempting a repair, we must determine 'why' the failure occurred.

Having assembled all of the facts together, we should now be able to formulate a cause for the failure. If the original weld was out of specification, it should be removed and the workpiece edges prepared. A repair weld can be produced according to the welding procedure specification and by consulting the relevant ASTM or British standard.

In the most extreme conditions, a change in the design can be considered during the repair process. This is only acceptable if it has been positively determined that a flaw in the design caused the failure. However, over-welding, particularly the case when welding thinner gage steel can often add internal stresses, increase stiffness, and introduce further metallurgical transformations in the steel. In the long term, this may increase the susceptibility for the subsequent brittle fracture. In this case, the process selected should introduce minimum heat and residual stresses. Preheating and/or post-heating can also be used to minimize these properties.

Cracks must be removed completely by grinding back to the parent material. Repair welds are then subsequently produced using suitable filler metal or low-hydrogen electrode. If complete separation has occurred, then a joint has to be prepared. This process may involve introducing a backing plate to compensate for the volume of void. Following the repair, a preventative maintenance process should be initiated. Here a periodic examination of repaired structure is undertaken to identify visible fatigue cracks before failure occurs again.

The science of investigating the origins of weld failure is used to establish the causes for this failure and to determine a preventive strategy for avoiding future occurrence. Experience and an understanding of failure analysis are important in the long term to increase reliability of welded structures. 